\title{
Processo de Expatriação na Internacionalização: estudo de caso em uma empresa Brasileira
}

\author{
Shalimar Gallon ${ }^{1}$, Elem Rabelo Duarte Vaz ${ }^{2}$, Larissa Nardes do Nascimento ${ }^{3}$ \\ ${ }^{1}$ Faculdade Meridional (IMED) - shalimar.canfield@imed.edu.br \\ 2 Faculdade Meridional (IMED) - elemduartevaz@gmail.com \\ ${ }^{3}$ Faculdade Meridional (IMED) - lnardesn@gmail.com
}

\section{PALAVRAS-CHAVE}

Expatriação.

Gestão de Pessoas

Internacional.

Internacionalização.

Estratégia

Internacionalização.

Received 17.05.2018

Revised 13.09.2018

Accepted 19.09.2018

ISSN 1980-4431

Double blind review

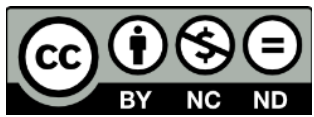

\section{RESUMO}

A expatriação é um processo corrente na condução dos negócios internacionais. No processo de expatriação, as práticas e políticas de Gestão de Pessoas devem estar alinhadas às estratégias empresariais a fim de contribuir para a consecução dos objetivos globais da organização. Assim, o objetivo deste estudo é analisar a influência da expatriação na estratégia de internacionalização através de um estudo de caso qualitativo em uma empresa brasileira e sua subsidiária portuguesa. A coleta de dados ocorreu por meio de um roteiro semiestruturado, contemplando 23 entrevistas. Na análise de dados, foi utilizado o software Max-Qda (2007) para organização das categorias de análise, baseada na técnica de análise de conteúdo. Os resultados mostram que a empresa está voltada para o mercado brasileiro com lento amadurecimento internacional e propicia o surgimento de novas configurações de empregados internacionais (cidadão do mundo, flexpatriado e gestor global). Apesar de a expatriação ser entendida como importante, é usada de maneira pontual; está voltada para levar a cultura da empresa para as unidades do exterior. Esse estudo contribui para que as organizações incluam a expatriação nas estratégias organizacionais e a percebam como um importante processo na globalização da empresa. Como sugestões de estudos futuros, deve-se analisar as diferenças no amadurecimento de internacionalização e as tendências para a gestão de expatriados das diferentes teorias de internacionalização. Se torna interessante entender, em longo prazo, o amadurecimento da internacionalização e, portanto, sugere-se um estudo longitudinal para acompanhar tal processo.

\section{KEYWORDS}

Expatriation. International Management of People. Internationalization. Strategy of internationalization.

\section{ABSTRACT}

The expatriation is an ongoing process in the conduct of international business. In the expatriation process, People Management practices and policies must be aligned with business strategies in order to contribute to the overall goals of the organization. Thus, the objective of this study is to analyze the influence of expatriation in the internationalization strategy through a qualitative case study in a Brazilian company and its subsidiary in Portugal. The data collection took place through a semi-structured script, contemplating 23 interviews. The data collection took place through a semi-structured script, contemplating 23 interviews. In the data analysis, the software Max-Qda (2007) was used to organize the categories of analysis, based on the technique of content analysis. The results show that the company is focused on the Brazilian market with slow international maturation and allows the emergence of new configurations of international employees (global citizen, flexpatriado and global manager). Although expatriation is understood as important, it is used in a timely manner; is aimed at bringing the company's culture to the foreign units. This study helps organizations include expatriation in organizational strategies and perceive it as an important process in the globalization of the company. As suggestions for future studies, one should analyze the differences in the maturation of internationalization and the trends for the management of expatriates of the different theories of internationalization. It is interesting to understand, in the long term, the maturation of internationalization and, therefore, a longitudinal study to accompany this process is suggested.

Revista de Negócios, v. 23, n. 2, p. 58-72, April, 2018. 


\section{Introdução}

A expatriação desempenha relevante papel na condução dos negócios e no direcionamento das estratégias internacionais devido à sua amplitude e à riqueza de conhecimento envolvido. É um processo que auxilia na interface e no alinhamento de políticas e práticas da Gestão de Pessoas (GP) com a estratégia empresarial, tendo, pois, importância na sua expansão global.

No entanto, quando acontece uma desconexão entre a estratégia de internacionalização da empresa e o processo de expatriação, implica a marginalização de um trabalho estratégico entre a empresa e suas subsidiárias (Vianna \& Souza, 2009). Caso os resultados de um projeto internacional não alcancem os objetivos propostos, a falha é atrelada à pessoa enviada ao exterior, em vez de ser percebida como inerente ao empreendimento - um projeto de alto risco e, por vezes, mal preparado que envolve diversas áreas da empresa e não somente o expatriado (Mccall \& Hollenbeck, 2003).

Em periódicos científicos, poucos modelos mostram a relevância do processo de expatriação na internacionalização da empresa (Gallon \& Antunes, 2013; Gallon \& Scheffer, 2013). Alguns estudos estão mais focados na internacionalização da empresa por si só, interessados em analisar a GP na internacionalização (Nogueira, Delgado, \& Barreto, 2013), tais como os modelos de Schuler, Budhwar \& Florkowski (2002) que descreve associações com componentes estratégicos que refletem preocupações com as metas da empresa; e Quintanilla (2002) tece uma crítica aos modelos de GPI por não englobarem a relação da matriz e da subsidiária. Os modelos citados não relacionam o processo de internacionalização (internacional, multidoméstica, global, transnacional), a orientação da GP (etnocêntrica, policêntrica, regiocêntrica, geocêntrica) e a expatriação.

Cabe enfatizar que há poucos estudos sobre expatriação na América Latina, inexistindo trabalhos que busquem criar uma teoria (Bianchi, 2011). Portanto, encontra-se nas teorias internacionais a base teórica para as pesquisas realizadas o que pode implicar em resultados divergentes da realidade das empresas de países menos desenvolvidos por não contemplar o seu contexto.

Schuler et al. (2002) concordam com Bianchi
(2011), ao relatarem que uma das lacunas na literatura é a carência de estudos em países menos desenvolvidos. Pouca atenção tem sido dada aos estudos de internacionalização de empresas, a partir de economias emergentes, como temática diferenciada nos negócios internacionais (Bartlet \& Ghoshal, 2006). Além disso, é importante analisar a expatriação de modo a compreender a visão de todos os envolvidos, e não somente dos gestores e da matriz. Ou seja, incluir a perspectiva dos empregados nacionais, internacionais e expatriados, bem como outras áreas que estejam envolvidas na internacionalização.

Frente a esse contexto, esse artigo analisa a estratégia internacional e o processo de expatriação, relacionando-os com diferentes níveis de internacionalização e orientações de GP, vista a ausência de estudos que façam essas relações. Assim, este estudo tem como objetivo analisar como o processo de expatriação influencia e é influenciado pelas estratégias de internacionalização em uma empresa brasileira, bem como mostrar a expatriação como um processo fundamental que orienta a estratégia de internacionalização das organizações, ainda que não seja tratado como tal.

A seguir, nas próximas seções será realizada uma explanação sobre internacionalização, GP e expatriação, seguida pelo delineamento metodológico e considerações finais do estudo.

\section{Internacionalização Empresarial e o Processo de Expatriação}

A internacionalização é uma decisão estratégica da empresa. A expatriação é um processo resultante da internacionalização das empresas; de quando elas passam de um contexto doméstico para um contexto internacional e global. $\mathrm{Na}$ mesma escala, o amadurecimento da expatriação e da gestão do expatriado acompanha este processo, desde uma perspectiva meramente de controle tradicional, por meio da matriz, passando pela gestão e pela coordenação de diferentes realidades, até a necessidade de estar presente em qualquer parte do mundo de maneira ágil (Gallon, Nevado, \& Antunes, 2013).

A expatriação é resultante dos movimentos internacionais e dependendo da estratégia e do amadurecimento da internacionalização, a organização passa a ter mais autonomia e maior diversidade de empregados. $\mathrm{O}$ amadurecimento das

Revista de Negócios, v. 23, n. 2, p. 58-72, April, 2018. 
empresas no âmbito internacional é analisado em seis estágios: nacional, exportadora, internacional, multidoméstica, global, transnacional.

O primeiro estágio é o de empresa nacional, aquela que detém suas operações no mesmo país onde está sediada. O segundo é o de empresa exportadora, a qual exporta produtos e serviços para outros países. A partir do terceiro estágio, as empresas podem ser consideradas multinacionais, havendo a possibilidade de evoluírem para internacional, multidoméstica, global e transnacional. Em geral, as multinacionais se distinguem das nacionais por cinco características: ambiente competitivo global, estratégia competitiva mais complexa, sistema de controle e coordenação global, mas diferenciado, estrutura organizacional mais complexa, cultura organizacional diferenciada (Muritiba, Vasconcelos, \& Muritiba, 2010).

A empresa internacional é o by the book do modelo americano, etnocêntrico, com réplicas da matriz, centradas na eficiência e usa as capacidades que possui para expandir-se nos mercados estrangeiros (Coelho \& Oliveira Jr, 2016; Bohlander, Snell, \& Sherman, 2003). Já a multidoméstica, está focada na resposta local e é mais desenvolvida que a empresa internacional, pois, na maioria das vezes, têm subsidiárias operando com unidades autônomas em vários países, para tratar de questões locais, sendo, geralmente empresas independentes (Spohr \& Silveira, 2012; Bohlander et al., 2003; Nogueira et al., 2009).

No formato de empresa global, o mínimo de recursos e ativos da matriz são descentralizados, ou seja, opera de uma forma semelhante a empresa internacional, porém possuiu um alto nível de coordenação e interdependência entre as subsidiárias e a matriz, para que a empresa esteja integrada globalmente (Bohlander et al., 2003; Nogueira et al., 2009).

O modelo transnacional é uma relação triunificante - local, internacional e global - e busca a otimização dos três modelos. No entanto, uma empresa transnacional tende a ter instalações especializadas, as quais buscam atender as necessidades locais da multidoméstica e a eficiência da global, através de métodos de coordenação, onde caracteriza uma integração global (Bohlander et al., 2003). Nesse conceito, há uma interação entre a subsidiária com a matriz, caracterizando uma organização em rede (Muritiba
\& Albuquerque, 2009).

Um novo modelo estudado por Doz, Santos e Willamson (2006), é a introdução da empresa metanacional, que contrapõem os conceitos apresentados anteriormente, , pois introduz a gestão de conhecimento em suas subsidiárias e, dessa maneira, deixarão de estar dependentes de sua matriz, bem como não procuram prosperar espalhando as vantagens adquiridas na matriz. Nesse sentido, a principal vantagem do modelo, não decorre do atravessar fronteiras entre os países; sua vantagem está em transcendê-las para além de seus limites (Sadzinski \& Borini, 2004). Esse tipo de empresa ainda não existe, sendo seu atual desafio $o$ de se transformarem em uma metanacional antes da concorrência (Doz et al., 2006).

Diante destes conceitos, a perspectiva global surge quando a organização deixa de analisar somente a empresa doméstica/local, na qual, provavelmente, está localizada a matriz, e passa a planejar as estratégias dentro de um contexto mais amplo, o global (Sadzinski \& Borini, 2004). Nessa perspectiva, a empresa pode adotar uma estratégia de GP etnocêntrica, policêntrica, geocêntrica ou regiocêntrica (Vance \& Paik, 2006).

A etnocêntrica mantém o maior controle na matriz, para a integração e a coordenação eficaz entre as unidades no exterior (Nogueira \& Barreto, 2013) e as principais tomadas de decisão são realizadas na matriz corporativa (Vance \& Paik, 2006). No entanto, uma orientação etnocêntrica pode levar à miopia cultural ou a uma falha geral da empresa em compreender as diferenças do país anfitrião, as quais podem exigir diferentes abordagens e modelos de gestão (Nogueira \& Barreto, 2013). Neste caso, a orientação policêntrica é mais coerente, principalmente em uma empresa multidoméstica, pois exige trabalhadores do país da subsidiária para participarem da gestão da organização (Nogueira \& Barreto, 2013). A orientação policêntrica ameniza barreiras linguísticas e dificuldades de adaptação cultural enfrentadas pelos gestores expatriados e por suas famílias (Vance \& Paik, 2006).

A estratégica de GP geocêntrica pressupõe que os empregados mais qualificados devem ocupar cargos gerenciais importantes, independentemente da nacionalidade. As empresas que seguem a orientação geocêntrica tendem, portanto, a ter uma cultura corporativa mais forte $\mathrm{e}$ unificada, além de um gerenciamento de 
informações mais eficaz, visto que as pessoas já não se sentem ligadas por laços culturais (Vance \& Paik, 2006).

Por fim, a orientação regiocêntrica promove a interação entre expatriados das subsidiárias no mesmo país (Nogueira \& Barreto, 2013). Esta abordagem pode ser benéfica para as empresas que não têm gerentes globais treinados. Como resultado desta rotação de trabalho, os gerentes, em diferentes localizações e níveis, tornam-se membros de redes informais de informação, com base nessas relações estabelecidas (Nogueira \& Barreto, 2013).

Pelo exposto, a presente pesquisa entende que todas as empresas, independentemente do modo de entrada no contexto internacional, lidam com pessoas e devem ter uma GP para atender todos os empregados espalhados pelo mundo. Contudo, normalmente, elas só se dão conta da necessidade de tal estrutura quando já têm um amadurecimento internacional. Além disso, a demanda por expatriados de nível operacional e tático é corriqueiramente mais frequente (inclusive pela maior proporção de empregados do nível operacional e tático em relação aos do nível corporativo), e mesmo assim não há, normalmente, uma estratégia ligada à internacionalização.

Em relação à expatriação, inicialmente, a necessidade da empresa é levar o conhecimento e, por isso, há uma orientação etnocêntrica. Neste contexto, a empresa foca seus objetivos nas informações que os expatriados devem levar para as subsidiárias, com foco na missão em si, porque a atividade do expatriado é ir, desenvolver seu trabalho e voltar.

Ao voltar, o conhecimento trazido pelo trabalhador através da repatriação pode facilitar o processo de implementação de políticas e práticas de GPI, ajudando a empresa a se tornar global. Com base no feedback da repatriação obtido por gestores da subsidiária e pelo próprio repatriado, podem ser encontradas tanto novas deficiências e estratégias como a necessidade de futuras expatriações. As organizações perceberam que as pessoas, ao voltarem, demonstravam maior conhecimento da empresa, indiferentemente do cargo assumido, porém, muitas vezes não conseguem lidar com a repatriação levando ao desperdício do investimento em capital humano e financeiro e tornando a repatriação o fim de um ciclo, sem maiores contribuições.

Isso pode estar relacionado à falta de visualização e de realização de estratégias e/ou políticas e práticas de expatriação. Assim, um dos desafios na etapa de repatriação, é a dificuldade de reter o empregado na empresa, quando esta não possui políticas e práticas que deem suporte a essa fase. A experiência obtida pelo repatriado revestese de grande relevância, não somente para ele, mas também para a empresa, inclusive financeiramente, pois os gastos demandados por treinamento, preparação e benefícios são altos.

A ausência de um modelo de expatriação que contemple fases e práticas corrobora a dificuldade de se ter um planejamento desse processo de internacionalização, o que impede a visualização do conhecimento que envolve cada uma de suas fases. Entender quais práticas estão interligadas com esse processo é igualmente necessário, para que se possam compreender impactos, implicações e resultados da expatriação como um processo de gestão.

O planejamento da expatriação também se torna importante em função das peculiaridades inerentes às diferentes configurações de expatriados (flexpatriado, impatriado, repatriado, patriado, empregado global, transnacional ou cidadão do mundo) envolvidos nesse processo. Há diversos conceitos que caracterizam as missões internacionais, os quais são diferenciados em função do trabalho a ser desempenhado, da duração da missão e da quantidade de viagens realizadas no período e demandam políticas e práticas diversas da GP para suprir as necessidades dos expatriados.

A expatriação é realizada em diversos níveis dentro da empresa, desde o operacional até o corporativo, o que também impacta sua configuração. Aparentemente, expatriado, repatriado e impatriado são conceitos relacionados com os níveis mais básicos da empresa (do operacional até o gerencial), sendo os outros conceitos relacionados com a gestão estratégica (do nível gerencial até o corporativo). Isso ocorre em função das estratégias e dos objetivos que a organização traça para as expatriações.

Bianchi (2011) afirma que o aumento do número de profissionais expatriados é uma opção estratégica para estruturar o modelo de gestão, enfatizando a relevância da expatriação nas estratégias de gestão, tanto no desenvolvimento individual como no desenvolvimento organizacional. Da mesma forma, Nunes, Vasconcelos e Jaussaud (2008) defendem que a expatriação se insere no âmbito organizacional,

Revista de Negócios, v. 23, n. 2, p. 58-72, April, 2018. 
ligando a GP à gestão estratégica. A expatriação demanda, portanto, que suas políticas e práticas estejam alinhadas às estratégias da organização (Tanure, Evans, \& Pucik, 2007), por estar relacionada com o negócio da empresa e não somente com a GP.

Com base nesses pressupostos, o presente estudo explora o processo de expatriação na perspectiva estratégica e não na operacional/ micro-organizacional, como vem sendo tratado na literatura corrente sobre este tema. O processo de expatriação facilita a troca de informações entre a GP da matriz e a GP da subsidiária, além de concentrar as informações para as novas estratégias internacionais, por meio do feedback da missão e dos repatriados. As estratégias determinam a estrutura corporativa a ser seguida (internacional, multidoméstica, global, transnacional) e a orientação da GP (etnocêntrica, policêntrica, geocêntrica), influenciadas pelo mercado de atuação e por fatores sociopolíticos e legais, sendo essas decisões essenciais para a estratégia internacional da empresa.

Apesar de existirem modelos de expatriação, ainda não há uma teoria fundamentada sobre a temática. A proposição para o desenvolvimento do estudo sugerido é abordar a expatriação como um processo dentro da estratégia internacional, como algo maior dentro de uma empresa, superando o foco de mera prática de GP. A partir do entendimento que a expatriação não é o simples movimento interno do empregado na empresa, o processo adquire maior importância e, possivelmente, receberá enfoque estratégico. Há, pois, necessidade de um modelo que contemple as práticas de todas as etapas do processo de expatriação, além de mostrar seu papel na estratégia de internacionalização.

\subsection{A internacionalização das empresas brasileiras} em Portugal

Portugal tem uma localização estratégica para as empresas brasileiras, sendo um dos cinco mercados mais visados por elas, de acordo com uma pesquisa realizada com 37 empresas (Cechella, 2009a). Em 2007, o Brasil estava entre os 20 maiores investidores estrangeiros em Portugal, à frente de alguns países tradicionais investidores no exterior. Em Portugal, estão algumas empresas com capital brasileiro reconhecidas internacionalmente. Várias pequenas e médias empresas utilizaram este país para o início de sua internacionalização em diversos setores da economia (Cechella, 2009a; 2009b), mostrando a relevância da relação de internacionalização entre os dois, pois é por meio do processo de internacionalização como um movimento estratégico que as empresas podem diversificar seus clientes e aumentar a exposição a potenciais parceiros comerciais (Varejão, 2013).

A empresa pesquisada, no referido estudo, acredita ser o potencial humano a principal força para o processo de internacionalização. A tecnologia utilizada, a imagem, a marca e a experiência no mercado local constituem os principais motivos para investir em Portugal. Os fatores relacionados com o ambiente externo são os menos relevantes, eles são representados por acordos comerciais com o Brasil e por acordos com empresas (Cechella, 2009a). Outro motivo para investir em Portugal pode estar relacionado com o fato de que as empresas trabalham mais facilmente no País devido a fatores ligados à afinidade cultural, o que propicia melhor compreensão do ambiente no qual estão inseridas e aumenta a possibilidade de parcerias com empresários portugueses, o que, dependendo do tipo de empreendimento, pode ser importante especialmente na fase inicial do processo (Cechella, 2009a). Sendo assim, a afinidade cultural, a aproximação linguística, e os laços históricos que unem Brasil e Portugal (Costa, 2005; Sousa, 2009) são elementos facilitadores da integração entre os países (Magrinho, 2009).

No geral, grandes semelhanças na cultura organizacional foram detectadas entre Brasil e Portugal. Nesse contexto, a adaptação aos costumes locais, a capacidade de liderança e a reação ao ambiente são os elementos principais que a empresa brasileira considerou críticos para o sucesso em Portugal (Cechella, 2009a).

Em uma pesquisa realizada por Cechella (2009b), com três empresas brasileiras que atuam em Portugal (Banco Itaú S/A, CSN/ Lusosider S/A e WEG S/A), foram levantados outros fatores que estimularam os investimentos brasileiros em Portugal. A posição geográfica de um em relação ao outro é um aspecto essencial na medição do potencial de comércio e investimento. A presença em mercados geograficamente próximos confere maior segurança às empresas, pois o grau de incerteza e de complexidade associado às operações é bastante menor quando comparado ao Revista de Negócios, v. 23, n. 2, p. 58-72, April, 2018. 
de mercados longínquos (Varejão, 2013). O Brasil, no contexto da América do Sul, e Portugal, no da UE, fazem parte de plataformas continentais distintas e, portanto, ao visarem a esses mercados, podem tirar vantagem por serem pontos estratégicos. A estabilidade econômica e política dos dois também influencia no IDE, pois reduz a incerteza do investimento (Cechella, 2009b).

O Brasil, neste século, vai redescobrindo Portugal. Em consequência do desenvolvimento empresarial também ocorre maior intercâmbio cultural e turístico, vindo a reforçar os laços de amizades. Com o tempo, certos preconceitos em relação a Portugal, há muito enraizados, vão sendo revistos. Ele passa a ser considerado não apenas um país moderno e dinâmico, como também detentor de uma localização estratégica, que possibilita acesso à ampla gama de mercados internacionais (Cechella, 2009a).

\section{Procedimentos Metodológicos}

Para obter resultados que possam mostrar a relação da expatriação com a estratégia de internacionalização, a pesquisa de campo foi baseada em um estudo de caso, pois conta com o resultado de múltiplas fontes de evidência, com os dados convergindo de maneira triangular, e beneficia-se do desenvolvimento anterior das proposições teóricas para orientar a coleta e a análise de dados (Yin, 2010). Para tanto, o estudo de caso explorou as estratégias de internacionalização da empresa e a relação da expatriação, de acordo com a maturidade de internacionalização, sendo a empresa Elétrica a unidade de análise da pesquisa. Levantaram-se também as práticas de expatriação utilizadas pela empresa e sua subsidiária e como elas se relacionam com as estratégias de internacionalização (Yin, 2010).

A pesquisa tem caráter qualitativo, pois objetiva analisar os fenômenos, buscando depoimentos que se transformem em dados relevantes (Demo, 2000). Esse tipo de pesquisa permite descrever, com riqueza de detalhes, os fenômenos como eles estão situados e incorporados nos contextos locais (Johnson \& Onwegbuzie, 2004), possibilitando, assim, melhor compreender o ambiente em que o caso ocorre, devendo ser analisado em uma perspectiva.

A empresa escolhida para este estudo foi a Elétrica (Santa Catarina - Brasil), considerada uma empresa de grande porte. No ano de 2011, a Elétrica faturou $\mathrm{R} \$ 6$ bilhões e empregava $26 \mathrm{mil}$ pessoas. A empresa tem origem brasileira, do ramo industrial, com processo de internacionalização e expatriação estruturados e com expatriados brasileiros.

A coleta dos dados foi realizada por meio de entrevistas com base em um roteiro semiestruturado desenhado a partir do referencial teórico exposto no presente estudo e foi melhor organizado conforme o campo foi sendo explorado. Foram utilizadas ferramentas de conversação via internet, como o Skype que possibilita a realização de entrevistas individuais (Janghorban, Roudsari, \& Taghipour, 2014), para a realização das entrevistas ou para retomar algum ponto da entrevista que precisava ser esclarecido, encontrando-se a pessoa a grande distância. Além das entrevistas, foram realizadas consultas a documentos, sites, material publicitário, com o objetivo realizar a triangulação dos dados (Yin, 2010).

A coleta de dados começou no Brasil e posteriormente em Portugal. Inicialmente, desenvolveu-se um estudo exploratório com gestores, aqui denominados de coadjuvantes. Essa etapa buscou fazer um levantamento sobre a expatriação e o contexto português e brasileiro, no intuito de dar suporte e melhor entendimento às respostas dos entrevistados protagonistas (empregados das empresas estudadas).

No total, foram analisadas 23 entrevistas. Não houve distinção por sexo, idade ou cargo. As pessoas que tinham conhecimento sobre gestão estratégica, internacional ou de expatriação e tivessem estado em alguma operação lusobrasileira foram convidadas a participar da pesquisa. Mantidos os contados, havendo aceitação do convite e aprovação da empresa (quando necessária), realizaram-se as entrevistas.

A análise de informações consistiu em dados primários (entrevistas) e secundários (entrevistas cedidas para jornais, documentos de divulgação, site das empresas e material interno enviado pelos entrevistados) (Bauer, 2002). Para a análise dos textos, foi utilizada a técnica de análise de conteúdo, a qual busca avaliar e analisar sistematicamente o conteúdo das mensagens, que, na presente pesquisa, são as entrevistas (Humphreys, 2011). Após a coleta de dados, em um primeiro momento, foi realizada a transcrição das entrevistas e uma leitura flutuante, a fim de

Revista de Negócios, v. 23, n. 2, p. 58-72, April, 2018. 
estruturar as categorias. A partir disso, foi utilizado o procedimento de análise categorial, no qual é fornecido o sistema de categorias e os dados são distribuídos, da melhor maneira possível, à medida que vão sendo encontradas as relações (Bardin, 2009).

Para atender os critérios dessa técnica, a unidade de análise escolhida foram as perguntas realizadas aos entrevistados. Nesse caso, partiu-se da análise de quatro macrocategorias a priori: gestão de pessoas, internacionalização, expatriação e diferenças entre os países, visto que esses foram os temas norteadores da pesquisa. Conforme o trabalho de categorização era desenvolvido, as categorias primárias foram surgindo naturalmente e sendo organizadas com base no que foi abordado no referencial teórico. Durante e no final do processo de categorização, era realizada nova organização das categorias, caracterizando um processo contínuo.

Para organização e reestruturação das categorias foi utilizado o software Max-Qda versão 2007. Ele auxiliou a comparação dos estudos de caso, possibilitando melhor visualização de toda a pesquisa. A utilização do software, na investigação qualitativa, não a automatiza nem executa a análise, ainda que este apoio possa ter algum impacto sobre ela (Flick, 2002). Quem realiza a análise dos dados é o pesquisador; o programa apenas permite maior velocidade no manuseamento; busca e apresentação de dados; ligação entre dados; melhoria da qualidade da investigação, bem como aumenta a coerência dos procedimentos de análise.

\section{Análise dos Resultados}

Das quatro categorias iniciais 'gestão de pessoas'; 'gestão internacional'; 'processo de expatriação'; 'diferenças entre Portugal e Brasil' resultaram na categoria final: 'o processo de expatriação na estratégia de internacionalização em uma empresa brasileira', a qual é analisada a seguir.

Os resultados da pesquisa permitem evidenciar a importância da análise do modo de entrada da empresa em outro país. Dependendo do tipo de negócio no país estrangeiro, o espaço da matriz nas decisões da subsidiária pode variar. No caso de uma operação greenfield, o controle de políticas e práticas de GP encontram menos empecilhos do que em outros tipos de empresa e os expatriados são enviados conforme a política da matriz. No caso de aquisição, há cuidado com a cultura e as políticas preexistentes e os expatriados são enviados, inicialmente, para introduzir os processos da empresa. No caso de joint venture, leva-se em consideração tanto o contrato comercial estabelecido como a porcentagem de aquisição. No caso de uma participação minoritária, a demanda dos empregados brasileiros é realizada pelo parceiro empresarial.

A GP da Elétrica precisa, portanto, englobar diferentes contextos para desenvolver suas políticas. Com um papel direcionado para atender a área corporativa, a GP doméstica estrutura suas principais práticas para abranger todos os empregados - nacionais e internacionais. Por meio das práticas de cargos e salários e de treinamento, ela obtém as informações básicas sobre o quadro de pessoal da organização.

\footnotetext{
A gente mapeou o que era importante levar para o exterior. Foi aquilo que comentei sobre cargos e salários, treinamento e administração de pessoal, até para responder as três perguntas: quem trabalha, o que faz e quanto ganha. A gente tem um sistema de GP e usa para controlar as promoções e esse sistema está sendo implementado em algumas unidades (E16 Analista de GPI Brasil).
}

A GP corporativa e a pequena e burocrática GPI contribuem para a concepção de uma estrutura multidoméstica, direcionada para uma atuação passiva das subsidiárias na gestão da organização. Esse contexto evidencia o lento amadurecimento internacional da empresa. As práticas que poderiam contribuir para tal amadurecimento são focadas no conhecimento da matriz, como a Elétrica Knowledge que tem o aspecto de manual de instrução (percepção da entrevistadora, pelo modo como foram relatadas a existência e a funcionalidade da prática).

Frente ao contexto internacional, as relações históricas, culturais e econômicas entre Portugal e Brasil os tornam próximos, facilitando o envio de empregados brasileiros para Portugal. Os brasileiros levam a cultura da Elétrica por meio dos processos organizacionais realizados na matriz. Essa cultura é influenciada pelo contexto brasileiro, propiciando práticas que, por vezes, não são percebidas como necessárias em contextos mais desenvolvidos, como no caso de Portugal. O depoimento a seguir mostra as práticas sociais da GP brasileira desenvolvidas em Portugal e que, aparentemente, não são comuns no país lusitano.

Revista de Negócios, v. 23, n. 2, p. 58-72, April, 2018. 
Em termos do Brasil tu tens vários pontos: gestão de desempenho, fatores motivacionais. O Brasil é muito direcionado para a pessoa. Nós aqui tentamos, passamos uns filmes, fotografias, nós colocamos vídeos motivacionais, de forma que as pessoas percebam que não é preciso eu ter um momento de $1 \%$ ou $2 \%$ para sentir bem. Às vezes, basta nós estarmos mais atentos ao colega que está ao lado que está mais triste. E há muita gente que diz: 'eu tenho orgulho de trabalhar nesta empresa'. Nós somos uma multinacional brasileira com orgulho. Há muita vertente social que é passada e que as pessoas ficam agradadas com aquilo e realmente fazem o nome da Elétrica (E18 - Analista de GP Europa).

Apesar dos laços históricos, o contexto de cada país é bem particular. A língua comum apresenta diferenciações advindas do sotaque, do vocabulário local e do modo de organizar o pensamento, o que causa alguns desconfortos na relação entre os trabalhadores dos países. Isso é coerente com a pesquisa de Rocha, Mello e Maculan (2010) que revela que o povo português traduz literalmente termos estrangeiros (por exemplo: o dispositivo usado como apontador sobre a tela do computador, conhecido no Brasil como mouse, em Portugal se chama 'rato'). Influenciadas pela literalidade da cultura portuguesa, muitas vezes, certas situações podem ser confundidas pelos brasileiros com grosseria, descaso ou falta de esperteza. No contexto organizacional, isso repercute na padronização de documentos da empresa, como relata E13 (VicePresidente EUA):

A gente sente dificuldade de língua, por exemplo, a gente tem dificuldade básica do tipo: termos que eu uso no Brasil são diferentes. Por exemplo, um termo bem técnico na nossa área são 'as cabeças de bobina': é a parte de cima do elétrico. O Brasil inteiro chama de cabeça de bobina; o mundo inteiro chama de cabeça de bobina, traduzindo né e Portugal chama de 'testa'. Então, você imagina a confusão documental que foi para se fazer entender e ter que traduzir de 'português para português'.

As empresas tendem a implementar unidades em mercados culturalmente próximos, para evitar delongas que retardem o amadurecimento da subsidiária. Como exposto no depoimento anterior, no caso da Elétrica em Portugal, essa aproximação não facilitou a entrada da empresa brasileira no mercado lusitano. A resistência de trabalho dos empregados portugueses - "dos colonizados comprarem a empresa dos colonizadores" (E13 -
Vice-Presidente EUA) - e a própria transição de gestão em uma aquisição tornaram a experiência em Portugal desafiadora, inclusive maior do que em alguns mercados críticos e distantes culturalmente do Brasil, como a Índia. Essa situação é relatada por diversos entrevistados da Elétrica (E10 - Supervisor de vendas internacionais Brasil, E13 - Vice-Presidente EUA e E14 - Assistente Técnico Europa).

De modo geral, a experiência internacional em Portugal é vista de forma positiva pelos expatriados. O E12 (Diretor Internacional Brasil) diz que foi "desafio entender essa cultura [portuguesa], de como conduzir isso, como não ser mal interpretado, mas foi gratificante, tanto que teve problemas culturais, problemas de gestão, mas aprendi muito com eles também". A percepção de aprendizado da experiência é compartilhada por outros entrevistados.

O contexto brasileiro influencia o panorama da empresa Elétrica, quando o assunto é expatriação. Existem alguns fatores estruturais que podem interferir nesse processo, principalmente em cidades de pequeno porte, como aquela em que está localizada a matriz da Elétrica. A infraestrutura necessária para a adaptação de uma pessoa estrangeira pode ser conseguida facilmente em cidades como São Paulo e outras capitais, mas nem sempre em lugares como a cidade que sedia a Elétrica, como relata o E12 (Diretor Internacional Brasil): "trazer estrangeiros para cá [Brasil]? Não vou dizer que não é plano da empresa. Já experimentamos. Tivemos dois ingleses que moraram aqui na cidade que tinham mobilidade, mas na hora que você coloca família, complica".

Imagine-se que um empregado é expatriado ao Brasil com sua família (cônjuge e filhos) e todos falam apenas o idioma inglês. Ele precisa estar em um local com condições estruturais para a ambientação de sua família, com uma escola bilíngue para os filhos e com oportunidades de emprego para o cônjuge. Isso não seria problema em uma cidade como São Paulo ou Rio de Janeiro, porém configura-se como uma dificuldade em localidades menores. Ressalva-se, no entanto, a dificuldade de trazer expatriados para cidades como São Paulo e Rio de Janeiro pela existência da violência e da repercussão que isso tem no exterior. O contexto brasileiro, além de não ser propício para receber expatriados, também dificulta a formação de parcerias internacionais, por causa da imagem negativa do Brasil no exterior.

Revista de Negócios, v. 23, n. 2, p. 58-72, April, 2018. 
Ele disse: 'sou o diretor de engenharia da empresa e eu não quero saber de negócios com o Brasil'. Deu aquele choque. 'Mas por quê?' 'Eu morei em Santos. Eu trabalhava lá e fui assaltado. E a minha mulher foi assaltada. E o meu filho, roubaram a bicicleta, os tênis e tudo. Nós ficamos seis meses. Eu não quero nem chegar perto do Brasil. E eu não estou de acordo e vou sair dessa reunião'. E o cara foi embora, na frente do presidente da empresa (E15 - Ex-Diretor Internacional Brasil).

Esse relato corrobora o etnocentrismo da matriz brasileira e a centralização de experiências e de conhecimento do mercado global em um restrito número de empregados. Com poucas pessoas dispostas e preparadas para enfrentar os desafios de uma missão internacional, os expatriados ocupam cargos de gestão em diferentes unidades; uma missão após a outra.

Eu já passei por diversas experiências. Hoje, eu sou praticamente responsável pela administração geral da empresa [dos EUA]. Uma empresa de 500 milhões de dólares; isso vai me dar uma experiência que pode me levar para qualquer outro lugar do grupo da Elétrica. Não necessariamente eu voltarei ao Brasil; pode ser que eu volte ao Brasil, sim. No Brasil, a gente tem uma carência de sucessão. Nesse momento, eu diria que nos próximos 5, 10 anos, com certeza eu sou um dos nomes cotados para voltar para o Brasil. Mas eu não posso considerar que essa é a única alternativa. Eu diria que as chances são de $50 \%$ a $50 \%$ : considerando que tem mais filiais no exterior do que no Brasil, as chances do exterior são maiores (E13 - VicePresidente EUA).

A Elétrica comprou uma fábrica nos EUA, em 2011 no final do ano. Então era importante ter alguém da área comercial lá, que conhecesse os produtos aqui do Brasil. Então, se mandou um engenheiro da área comercial para lá, mas porque era importante, não era para desenvolver esse cara, entendeu? Pode até ser que tenha um objetivo secundário, mas o principal é para suprir uma necessidade, uma demanda (E16 - Analista de GPI Brasil).

Os depoimentos revelam que o desenvolvimento das pessoas é um objetivo secundário da empresa, mas, por vezes, é o objetivo principal do empregado, o qual vislumbra seu crescimento dentro da empresa. As principais estratégias para a expatriação são "garantir pessoas confiáveis, dirigindo os negócios da empresa, pessoas competentes e que a estratégia da empresa esteja alinhada entre a matriz e o exterior" (E16 Analista de GPI Brasil). Isso evidencia que a expatriação está relacionada com a estratégia de internacionalização da empresa, com foco na segunda fase da experiência.

Em menor grau, mas também presente, desenvolver um pouco essas pessoas para os desafios futuros da empresa. $\mathrm{O}$ atual presidente da empresa, um ano antes de ele assumir a empresa, foi expatriado para Portugal. Claro, eu não acompanhei na época, mas imagino que o objetivo dessa expatriação fosse dar uma experiência internacional para ele antes de assumir a presidência. Provavelmente ele já estava escolhido para ser o presidente, só foi pedido para ele entender um pouco mais desse dinamismo. Atualmente, há um plano de sucessão. O plano de sucessão é mais ou menos o seguinte: quem são os candidatos para ser o próximo presidente? Bom, tem o negócio dos elétricos, do produto B e do produto C. Quem são os candidatos a ser o diretor da Elétrica do produto D? E assim por diante ele é escalonado nas experiências internacionais (E16 - Analista de GPI Brasil).

A internacionalização da empresa e o processo de expatriação dão mais visibilidade para a empresa, atraindo melhores empregados e a tornando mais valorizada no mercado. $\mathrm{O}$ processo de expatriação vem amadurecendo desde o início da primeira missão, como relata o E12 (Diretor Internacional Brasil). Com o retorno dos expatriados para a matriz e o despreparo da empresa em entender a repatriação, há um direcionamento da GPI para ampliar a expatriação e incorporar a repatriação nesse processo. Isso permite analisar a expatriação em três fases, como proposto nessa tese, mas com foco no indivíduo na retenção do empregado - e não na forma a integrar o conhecimento que essa pessoa traz na empresa.

É um negócio que envolve muito a empresa. Você não tem ideia como é fazer uma gestão de executivos a nível internacional, isso envolve muito a empresa. A gente é bastante cobrado em relação a isso, porque são as pessoas que comandam a empresa. Então, ela não pode perder essas pessoas, elas têm uma quantidade de informações importantes, chaves. Uma coisa é talvez me perder - eu sei bastante informação confidencial da empresa - mas não sei tanto. Agora, um executivo, ele tem acesso a questões de preços, estratégias da empresa, como é que a empresa se posiciona, como é que ela remunera, então, é muito importante essas pessoas. Além disso, eu acho que a empresa se tornou mais visível no mercado, então, isso aumenta a atratividade dos funcionários da empresa. Imagine o seguinte: uma empresa do tamanho da Elétrica, mas que não seja internacionalizada; a atratividade de funcionários no mercado vai ser bem menor do que trabalhar em uma empresa

Revista de Negócios, v. 23, n. 2, p. 58-72, April, 2018. 
multinacional. Então, a empresa tem que ter estratégias mais eficientes para reter os funcionários, remunerando, oferecendo benefícios, plano de carreira (E16 - Analista de GPI Brasil).

Ressalta-se que a necessidade em descentralizar o conhecimento do indivíduo e em promover sua dissolução por meio de práticas organizacionais, pois, caso a pessoa se desligue da empresa, esse conhecimento não sairá com ela. Falta essa visão para a empresa Elétrica no processo de expatriação. O E13 (Vice-Presidente EUA) relata a existência de "sessões de feedback, onde eles [repatriados] falam para todo mundo das suas experiências. Isso ajuda bastante essa troca de experiência". No entanto, poucas ações foram levantadas na pesquisa com o direcionamento para a retenção e a perpetuação do conhecimento. Isso pode estar relacionada com a área à qual $\mathrm{o}$ entrevistado citado está vinculado: a engenharia, que, bem como a área de vendas e assistência técnica, tem maior fluidez de informações que outras áreas, de acordo com o depoimento dos entrevistados.

Apesar dos custos que a envolvem, a expatriação é vista como um processo importante: "escolher uma pessoa experiente aqui do Brasil, isso praticamente vale para qualquer expatriação" (E16 - Analista de GPI Brasil). Isso porque os expatriados buscam desenvolver a unidade a fim de torná-las independentes da matriz - consoante com a perspectiva de multidoméstica da empresa. O E12 (Diretor Internacional Brasil) salienta que "onde alguns brasileiros foram com bastão de liderança, eles implantaram. Onde os brasileiros não foram com bastão de liderança, ficou a liderança num local, numa área". Essa divergência está atrelada à informalidade de algumas práticas e objetivos da expatriação na empresa, pois, dependendo do gestor que conduz o processo, há diferentes direcionamentos indicados para o expatriado, como relata o E17 (Gerente de Mercado Internacional Europeu): "quando tem que tomar grandes decisões, nós buscamos essas pessoas [gestores locais]: 'olha trabalhem junto conosco, deem ideias', e a gente vai dando corda para eles ficarem mais independentes, que aí, daqui a pouco quando eu tiver que sair, eu saio e eles não sentem muito".

Consoante com a estratégia de internacionalização da empresa, com o desenvolvimento das lideranças locais, é consolidada a autonomia das unidades, tornando a presença do expatriado dispensável. O que direciona para a diminuição da atuação dos expatriados, conforme ocorre o amadurecimento da unidade.

Tende a diminuir nas empresas que já estão se estruturando. Mas tende a aumentar nas novas aquisições. E nós, provavelmente, seremos os últimos expatriados aqui [em Portugal]. Eu, como entrei por último aqui, como expatriado faz três anos. Tem o E17 (Gerente de Mercado Internacional Europeu) que já está há seis e o E14 (Assistente Técnico Europa) que está há quase cinco anos. Então, essas pessoas tendem a morrer aqui porque a cultura já está bem ligada com as pessoas. Em uma empresa nova, muitas vezes, tu precisa de uma integração com o Brasil. Eles vão buscar aí se tem uma pessoa que conheça as pessoas lá dentro da Elétrica (E19 - Gerente de Vendas Europa).

Se tu, sempre que precisar, mandar alguém da matriz para fazer alguma coisa acontecer, estará criando uma relação de dependência que não é muito saudável, a não ser que tu queira uma cultura impositiva, não quer nem saber da realidade local. Então, a expatriação tem que ser uma ferramenta, mas não pode ser uma ferramenta em si (E13 - Vice-Presidente EUA).

Esse amadurecimento das unidades e a experiência internacional da empresa Elétrica possibilita entender o contexto externo e agir estrategicamente em relação à demanda de expatriados. Dependendo do amadurecimento da operação, da cultura local e do cargo de destino a ser preenchido, há diferentes decisões implementadas para o preenchimento de cargos internacionais.

Nas filiais mais novas tu dificilmente manda um
brasileiro sozinho. É suicídio. Tu normalmente manda
um brasileiro e coloca alguém [local] grudado com
ele. Na China, é inevitável. Na Índia, é inevitável.
Aqui nos EUA, é um país mais adaptável, está muito
próximo da nossa cultura, depende muito da região,
óbvio. Na Europa, depende do país. Tem países que
não aceitam o estrangeiro, e aí tem a rejeição local.
Então, tu também tem que pesar a rejeição local. A
gente já teve um caso de uma pessoa de nível
relativamente alto na Elétrica, posição gerencial, que
foi expatriado e o mercado rejeitou; não por problema
de performance, mas por puro preconceito. Isso não
vale só para brasileiro (E13 - Vice-Presidente EUA).

A empresa conta com um novo projeto: Elétrica 20-20. Com esse projeto, a internacionalização da empresa tende a aumentar e, consequentemente, elevar o número de expatriados, visto que "é difícil fazer uma

Revista de Negócios, v. 23, n. 2, p. 58-72, April, 2018. 
internacionalização sem ter alguém da matriz. Comprar uma coisa sem a interferência de algum expatriado brasileiro é quase que impossível" (E19 - Gerente de Vendas Europa).

Porque nós só podemos obter esse resultado se a gente tiver cada vez mais filiais que tenham o DNA da Elétrica. Para ter o DNA da Elétrica, a gente tem que ter alguém lá. Então, tenho certeza que a gente vai ter continuidade da expatriação porque sempre a gente vai precisar ter alguém nosso lá fora. A Elétrica vai continuar comprando empresas, fazendo empresa e tudo se conclui que precisa colocar alguém teu de confiança. E pelos planos que a Elétrica tem, vai aumentar. (...) Temos em torno de 80 (E11 - Diretor de GP Corporativa Brasil).

Esse projeto direciona os esforços da matriz e de todas as unidades para atingir a meta proposta. Desse modo, de forma ampla, a Elétrica tem amplitude global para os seus negócios, mas ainda é muito incipiente e desintegrada, como relata o E17 (Gerente de Mercado Internacional Europeu): "você vê duas realidades diferentes em tamanho, mas não vê em estratégia, porque a estratégia é praticamente a mesma; nós todos seguimos. A Elétrica tem o grande plano que é o 20-20: faturar 20 bilhões no ano de 2020 e nós temos que acompanhar".

A expatriação da empresa Elétrica, consoante com a estratégia de internacionalização e a orientação da GP, tem a perspectiva de processo de GP, mas ainda não é tratada como tal. Alguns entrevistados entendem e sinalizam a importância do processo, incluindo a repatriação, mas, de modo geral, esse direcionamento não foi identificado na empresa.

A expatriação faz sentido se tu tiver profissionais flexíveis, tanto para ir quanto para voltar. Se tu tiver profissionais flexíveis em um caminho só, ela é uma ferramenta limitada. Então, esse também é um probleminha que a gente tenta evitar. Mas ela é uma ferramenta, a estratégia não depende só disso, mas ela é uma ferramenta para implementar a estratégia (E13 - Vice-Presidente EUA).

A estratégia de internacionalização baseada na concepção de empresa multidoméstica, que proporciona papel passivo das unidades do exterior na gestão da empresa, e a influência da cultura familiar da Elétrica propiciam que ela esteja voltada para o mercado brasileiro, como se ele fosse o centro do mundo, deixando de considerar a contribuição internacional. Visualizando o contexto internacional e a situação político-social do Brasil, bem como sua emergente economia, a Elétrica tem longo caminho pela frente para amadurecer e tornar-se uma empresa global.

Conforme o exposto, o expatriado, em seu conceito corrente, pode vir a ser absorvido pela internacionalização da empresa. Entretanto, pode aparecer com uma nova configuração como as que já foram sinalizadas pelos entrevistados (cidadão do mundo, flexpatriado e gestor global).

Por todo exposto, as principais categorias que emergiram em relação ao processo de expatriação na estratégia de internacionalização foram que a empresa está voltada para o mercado brasileiro com lento amadurecimento internacional da Elétrica; o contexto brasileiro é um fator dificultador para que a empresa tenha impatriados; a gestão do conhecimento voltada para as informações brasileiras, com caráter de manual; apenas algumas área desenvolvem ações para aproveitar ofeedback do repatriado; as experiências internacionais da Elétrica contribuem para melhor tomada de decisão quanto à presença de expatriados; menor presença de expatriados conforme a unidade amadurece; o amadurecimento internacional propicia o surgimento de novas configurações de empregados internacionais (cidadão do mundo, flexpatriado e gestor global); a influenciada pela estratégia multidoméstica, a expatriação está focada na subsidiária (segunda fase do processo), ou seja, há pouca contribuição para a matriz; e a expatriação é entendida como importante, mas é usada de maneira pontual; está voltada para levar a cultura da empresa Elétrica para as unidades do exterior.

\section{Considerações Finais}

As análises deste estudo permitiram entender que o processo de expatriação da Elétrica ainda está em fase de desenvolvimento, o que interfere no amadurecimento do processo de internacionalização. A Elétrica ainda precisa se desenvolver; ela é internacional, mas não é internacionalizada. A empresa está focada na matriz, apresentando etnocentrismo nas estratégias, inclusive na GP. Isso implica na transferência de práticas e políticas da matriz para as subsidiárias mostrando a imaturidade da internacionalização das empresas, visto que não propicia uma gestão global ou transnacional. No entanto, está desenvolvendo a concepção multidoméstica, possibilitando à subsidiária ter maior

Revista de Negócios, v. 23, n. 2, p. 58-72, April, 2018. 
independência. Falta, porém, apresentar um papel ativo na estratégia.

A Elétrica entende que a expatriação é a missão em si, um processo glamoroso na qual os expatriados são tratados como pessoas 'escolhidas' para representá-la. Para Elétrica, o objetivo da expatriação e da estratégia de internacionalização está focado em preencher uma demanda local, no curto prazo.

A Elétrica está amadurecendo como empresa multidoméstica e apresenta uma GP etnocêntrica, a qual envia as diretrizes para a subsidiária no exterior, pois a GP da subsidiária em Portugal desenvolve atividades burocráticas e operacionais e depende das decisões tomadas na matriz. Faz expatriações mais pontuais, isso sinaliza maior dependência dos expatriados na internacionalização da empresa muito em função, do momento internacional vivido pela Elétrica.

Assim, a principal contribuição do presente estudo foi entender a expatriação como um processo que influencia o amadurecimento internacional da empresa e tem diferentes objetivos na estratégia internacional. Analisando a literatura consultada e as entrevistas realizadas, verifica-se que as pessoas ligadas à expatriação não a mencionam como um processo, tal como é abordado nesse estudo, mas ao relatarem as etapas, manifestam terem a percepção de processo. Ou seja, ainda não há uma noção de processo de expatriação implantada na organização, mas, quando posta em prática, não é possível dissociar uma etapa da outra, levando ao entendimento de processo.

A partir das entrevistas, pode-se perceber que as empresas brasileiras pesquisadas ainda não sentiram a necessidade de ter uma gestão que englobe os empregados internacionais. Esses recém vêm voltando de suas expatriações e as empresas estão agora despertando para entender as implicações de expatriações malsucedidas. As relações de trabalho mudaram e as abordagens de GP continuam querendo colocar seus empregados dentro de padrões que se alteram constantemente, principalmente quando assumem o âmbito internacional. As empresas demandam empregados com diversas competências, no entanto não apresentam políticas e práticas para tornar isso um diferencial estratégico e, principalmente, não conseguem lidar com tamanha diversidade cultural. Entretanto, elas não sobreviverão no mercado, fechando-se para empregados de uma nacionalidade só.

Atualmente, as empresas requerem uma GP e uma GPI que englobem a diversidade internacional e não foquem só nos expatriados. É necessário que elas estejam preparadas para receber os expatriados, os impatriados, os cidadãos do mundo e os empregados de outros países que não têm vínculos com a organização. Esses últimos, denominados autoexpatriados, contribuem com a formação de equipes multiculturais, mas que não fazem parte da GPI, pela inexistência de vínculo empregatício.

As empresas agora estão em um novo contexto e não cabe à GPI apenas cuidar dos expatriados, mas de todas as pessoas internacionalizadas da empresa, para obter proveito dessa riqueza cultural. Entretanto, por vezes, a área deixa a desejar, se restringindo a um papel meramente burocrático. Cabe um alinhamento da GP, visto que sua riqueza é maior que suas estruturas. Esse é o desafio da área: mostrar-se estratégica e atender todos os empregados, independente da nacionalidade, do vínculo empregatício de origem, de ser expatriado, repatriado, cidadão do mundo ou autoexpatriado.

Pelo exposto, fica evidente que a expatriação carece de pesquisas, abrangendo desde o entendimento sobre o que vem ser a expatriação até sua devida contribuição para as organizações. A expatriação é um processo amplo e requer ser debatido, a fim de acompanhar as mudanças globais e continuar trazendo contribuições para as empresas.

\section{Delimitações e Pesquisas Futuras}

A pesquisa teve como delimitação de estudo analisar empresa brasileira e sua subsidiária portuguesa, do ramo industrial, internacionalizadas e com processo de expatriação estruturado. Entretanto, algumas limitações surgiram durante a investigação destacam-se as questões culturais, e a língua que também foi um fator limitante. Embora a língua de ambos os países seja o português, por vezes, os conceitos usados em Portugal são entendidos de modo diferente do que no Brasil, podendo ser interpretados de maneira errônea.

Outra limitação relacionada ao campo de pesquisa foi não ter encontrado entrevistados que tivessem conhecimento sobre todas as questões propostas no protocolo de entrevista. Entretanto, a perspectiva de diversos níveis, cargos, hierarquias

Revista de Negócios, v. 23, n. 2, p. 58-72, April, 2018. 
e experiências mostrou um amplo panorama do processo. Além disso, como o assunto não é de conhecimento nem de responsabilidade de grande parcela de empregados nas organizações, o número de entrevistados tornou-se limitante.

Contudo, analisar as diferenças no amadurecimento de internacionalização e as tendências para a gestão de expatriados das diferentes escolas pode trazer novas contribuições para a área. Obviamente, os países emergentes também carecem de maior aprofundamento de pesquisa, necessitando serem focos de estudos para consolidar teorias referentes a seus contextos.

A presente pesquisa mostrou que se torna interessante entender, em longo prazo, o amadurecimento da internacionalização das empresas, levando em consideração alguns fatores destacados, como modo de entrada, setor de atuação e tempo de existência da empresa e de sua internacionalização. Sugere-se, portanto, um estudo longitudinal para acompanhar como ocorre a internacionalização, a relacionando com os conceitos de internacional, multidoméstica, global, transnacional e metanacional indicados nesse estudo, inclusive para encontrar novas dimensões da internacionalização.

Ademais, não foi encontrada a estratégia metanacional nos resultados. Por tanto, sugere-se investigar essa estratégia e as implicações que a mesma pode ter na expatriação organizacional, visto que a literatura sobre essa estratégia não contempla tal relação.

\section{Referências}

Bardin, L. (2009). Análise de conteúdo. Lisboa, Portugal: Edições 70.

Bartlett, C. A., \& Ghoshal, S. (2006). Organizar para a Efetividade Mundial: a solução transnacional. In: B. Tanure, \& R. G. Duarte (Eds.). Gestão Internacional. São Paulo: Saraiva.

Bauer, M. W. (2002). Análise de conteúdo clássica: uma revisão. In: M. W. Bauer, \& G. Gaskell (Eds.). Pesquisa qualitativa com texto: imagem e som: um manual prático. Petrópolis - RJ: Vozes.

Bianchi, E. M. P. G. (2011). Gestão e Carreira Internacional. Repatriação - construindo elos entre ciclos. Anais do Encontro Nacional dos Programas de Pós - Graduação em Administração, Rio de
Janeiro, Brasil, 35.

Bohlander, G., Snell, S., \& Sherman, A. (2003). Administração de Recursos Humanos. São Paulo: Pioneira Thomson Learning.

Cechella, C. (2009a). Os países emergentes com investidores internacionais: o caso das empresas brasileiras em Portugal. Tese de doutorado, Instituto Superior de Economia e Gestão, Universidade Técnica de Lisboa, Portugal.

Cechella, D. C. (2009b). Os investimentos brasileiros em Portugal: um estudo de três casos. In: J. R. Silva, \& A. C. Q. Barbosa (Eds.). Estado, Empresas e Sociedade. Um Mosaico LusoBrasileiro. Lisboa: Edições Colibri.

Coelho, D. B., \& Oliveira Jr, M. M. (2016). A internacionalização de empresas na agenda governamental contemporânea de desenvolvimento: reflexões críticas e analíticas para os negócios internacionais. Cadernos EBAPE.BR, 14, 527-550.

Costa, C. G. da. (2005). A cultura como fator dinamizador da economia. Os investimentos portugueses no Brasil. Lisboa: Universidade Técnica de Lisboa.

Demo, P. (2000). Metodologia do conhecimento científico. Atlas.

Doz, I., Santos, J. F. P. das, \& Willamson, P. (2006). O desafio metanacional. Como as empresas podem vencer a economia do conhecimento. Monitos: Lisboa.

Flick, U. (2002). Métodos qualitativos na investigação científica. Lisboa: Monitor.

Gallon, S., \& Antunes, E. D. D. (2013). O Processo de Expatriação na Estratégia Organizacional. Anais do $7^{\circ}$ Congresso Instituto Franco - Brasileiro de Administração de Empresas. VII Congresso do Instituto Franco - Brasileiro de Administração de Empresas (IFBAE), Tours, França.

Gallon, S., \& Scheffer, A. B. B. (2013). O processo de expatriação de executivos: Uma análise dos desafios da repatriação a partir de um estudo de caso em uma empresa do sul do Brasil. Anais do

Revista de Negócios, v. 23, n. 2, p. 58-72, April, 2018. 
VII Congresso Instituto Franco - Brasileiro de Administração de Empresas, Tours, França.

Gallon, S., Nevado, P. M. S. P., \& Antunes, E. D. D. (2013). Expatriação e Internacionalização: Alguns Contributos para a Expansão de Empresas Portuguesas e Brasileiras. In: J. R. Silva, \& A. C. Q. Barbosa (Org.). Desafios Econômicos $e$ Gerenciais das Relações Luso-Brasileiras. Uma década em perspectivas. Lisboa: Edições Colibri, 271-294.

Humphreys, A. (2011). Using Automated Content Analysis for Marketing Research. Working Paper, Northwestern University, Evanston, IL.

Janghorban, R., Roudsari, R. L., \& Taghipour, A. (2014). Qualitative Stud Health Well-Being. Retrieved April 25, 2017, from http://dx.doi.org/10.3402/qhw.v9.24152.

Johnson, R. B., \& Onwuegbuzie, A. J. (2004). Mixed methods research: a research paradigm whose time has come. Educational Researcher, 33(7), 14-26.

Magrinho, A. (2009). Portugal e Brasil: uma parceria para a economia global. In: J. R. Silva, \& A. C. Q. Barbosa (Eds.). Estado, Empresas e Sociedade. Um Mosaico Luso-Brasileiro. Lisboa: Edições Colibri.

Mccall, M. JR., \& Hollenbeck, G. P. (2003). Desenvolvimento de Executivos Globais. As lições da experiência internacional. Porto Alegre: Bookman.

Muritiba, P. M., \& Albuquerque, L. G. de. (2009). Características da Gestão Estratégica de Pessoas para as organizações Internacionalizadas. In: L. G. de, Albuquerque, \& N. P. Leite (Org.). Gestão de Pessoas. Perspectivas Estratégicas. São Paulo: Editora Atlas.

Muritiba, S. N., Vasconcelos, E., \& Muritiba, P. M. (2010). Conselhos de administração e estratégia de internacionalização. In: A. Fleury (Org.). Gestão Empresarial para a Internacionalização das empresas brasileiras. São Paulo: Atlas.

Nogueira, A. J. F. M., \& Barreto, M. S. P. (2013). Mentalidade global e RH internacional em empresas multinacionais brasileiras do segmento de construção pesada. Revista de Gestão, 20(4), 497-516.

Nogueira, A. J. F. M., Barreto, S., \& Delgado, M. P. (2009). Gestão de recursos humanos no processo de internacionalização. Anais dos Seminários em Administração, São Paulo, São Paulo, Brasil, 12. Recuperado em 12 junho, 2012, de http://www.ead.fea.usp.br/semead/12semead/resul tado/trabalhosPDF/752.pdf

Nogueira, A. J. F. M., Delgado, M. P., \& Barreto, S. (2013). Gestão de Recursos Humanos no Processo de Internacionalização. Internext, 7, 1-29.

Nunes, L. H., Vasconcelos, I. F. G. de, \& Jaussaud, J. (2008). Expatriação de Executivos. São Paulo: Thomsom Learning.

Quintanilla, J. (2002). Dirección de recursos humanos em empresas multinacionales: las subsidiarias al descubierto. Madrid: Prentice Hall.

Rocha, A. da, Mello, R. C. de, Maculan, A. M. D., \& Pacheco, H. F. (2010). Ivia: crescimento $e$ internacionalização. Revista de Administração Contemporânea, 14(6), 1158-1170.

Sadzinski, A. L., \& Borini, F. M. (2004). Do grande ao pequeno: a nova dimensão da competitividade global. Revista de Negócios, 9(1), 27-40.

Schuler, R. S., Budhwar, P. S., \& Florkowski, G. W. (2002). International human resource management: review and critique. International Journal of Management Reviews, 4(1), 41-70.

Souza, V. A. (2009). A evolução das relações lusobrasileiras numa perspectiva histórica. In: J. R. Silva, \& A. C. Q. Barbosa (Eds.). Estado, Empresas e Sociedade. Um Mosaico LusoBrasileiro. Lisboa: Edições Colibri, 2009.

Spohr, N., \& Silveira, F. F. (2012). Estratégia internacional de uma multinacional emergente brasileira: o caso JBS. Revista de Administração de Empresas, 52(3), 300-312.

Tanure, B., Evans, P., \& Pucik, V. (2007). A Gestão de Pessoas no Brasil. Virtudes e Pecados Capitais. Estudos de Caso. Rio de Janeiro: Elsevier. Revista de Negócios, v. 23, n. 2, p. 58-72, April, 2018. 
Vance, C. M., \& Paik, Y. (2006). Managing a Global Workforce: Challenges and Opportunities in International Human Resource Management. New York: M. E. Sharpe.

Varejão, J. C. de S. (2013). Internacionalização de Pequenas e Médias empresas em Portugal: Abordagem Programada vs Abordagem não Programada. Dissertação (Mestrado em Contabilidade e Administração). Instituto Superior de Contabilidade e Administração do Porto, Instituto Politécnico do Porto, Porto, Portugal.

Vianna, N. P., \& Souza, Y. S. de. (2009). Uma análise sobre os processos de expatriação e repatriação em organizações brasileiras. Revista de Administração e Contabilidade da Unisinos, 6(4), 340-353.

Yin, R. (2010). Estudo de caso: planejamento e métodos (3a ed.). Porto Alegre: Bookman. 